\title{
Yeni Medyada Kimlik İnşası: YouTuber Kimliğine İlişkin Bir İnceleme
}

\author{
İbrahim Etem Zinderen (Dr. Öğr. Üyesi) \\ Atatürk Üniversitesi, İletişim Fakültesi \\ ibrahim.zinderen@atauni.edu.tr \\ ORCID: 0000-0003-2921-4857
}

Başvuru Tarihi: 26.11.2019

Yayına Kabul Tarihi: 30.12.2019

Yayınlanma Tarihi: 24.01.2020

DOI: http://10.17680/erciyesiletisim.650956

\section{Öz}

Teknolojik gelişmeler, tüm dünyayı etki alanı içine alan yeni ve yapay bir iletişim ortamı doğurmuş; üretim, dağıtım ve paylaşımın bilgisayarlar üzerinden gerçekleştiği etkileşime dayalı bir yapı ortaya çıkarmıștır. Toplumsal ilişkilerin sanal bağlar/ağlar üzerinden yürüdüğü bu siber uzam, kimliğin sanal boyutta üretildiği bir alan olma özelliği kazanmıștır. Sanal kimlik; sanal dünyada inșa sürecine dayalı, idealize ve yapay bir kimlik temsiline denk düşmektedir. Sanal kimlik inşasının büyük oranda gerçekleştiği sosyal medya platformlarından biri de, çeşitli kategorilerde içerik üretebilme fursatı veren, bu yönüyle sıradan kullanıcıların aktif, etkileşimli ve medyatik hale gelmesinde etkili bir platform olan YouTube'dur. Kimlik temsili ve sanal kimlik inşası bağlamında YouTube'a odaklanan bu çalışma, sanal kimlik konusunu YouTuberlar ekseninde değerlendirmektedir. Çalışmanın temel amacı ise YouTuber kimliğini betimleyerek bu kimliğe ilişkin bir harita çıkarmaktır. Bu çerçevede Türkiye'de abone sayısı en yüksek iki YouTube kanalı örneklem olarak seçilmiş ve kimlik temsiline ilişkin betimsel bir analiz yapılmıştır. Analizler kanalların ilk ve son dönem videolarından birer örnek üzerinden detaylandırılmıştır. Çalıșma kapsamında ele alınan YouTuberlerın ortaya koyduğu yükselen imaj ve maddi güç özendirici bir nitelik taşımaktadır. Kimlik temsilleri ise sosyal ağlarda görülen mutlak mükemmellik gösterisine denk düşmektedir. Dolayısıyla incelenen YouTube kanallarında doğallığın yeniden üretildiği, doğal olanın yapaylaştığı, özgürlügün ve mutluluğun koşulsuz bir şekilde gerçekleștiği bir dünya tasviri dikkat çekmektedir.

Anahtar Kelimeler: Yeni Medya, Kimlik, Sanal Kimlik, YouTuber Kimliği. 


\title{
Identity Building in New Media: A Review on YouTuber Identity
}

\author{
İbrahim Etem Zinderen (Asst. Prof. Dr.) \\ Atatürk University Faculty of Communication \\ ibrahim.zinderen@atauni.edu.tr \\ ORCID: 0000-0003-2921-4857
}

Date Received: 26.11 .2019

Date Accepted: 30.12.2019

Date Published: 24.01.2020

DOI: http://10.17680/erciyesiletisim.650956

\begin{abstract}
Technological developments have created a new and artificial communication environment that covers the whole world, leading to an interactive structure where production, distribution and sharing take place by means of computers. This cyber space, where social relations are maintained through virtual links/networks, has become an area where identity is created in virtual terms. Virtual identity represents an idealized artificial identity that's built in the virtual world. One of the social media platforms where the virtual identity building process mainly takes place is the YouTube, which is effective in helping ordinary users become active, interactive and famous by enabling them to produce content in various categories. This research focuses on YouTube with respect to identity representation and virtual identity building, and evaluates the issue of virtual identity within the framework of YouTubers. The main purpose of this research is to describe and map out the YouTuber identity. In line with this purpose, two YouTuber channels with the highest number of followers in Turkey were selected as the sample group of the research and a descriptive analysis about identity representation was made. The analyzes were elaborated by giving one example for each of the early and late period videos of these channels. The rising image and financial power demonstrated by YouTubers represent an encouraging characteristic. ID representations correspond to the demonstration of absolute perfection seen in social networks. Therefore, in the YouTube channels examined, a depiction of the world where happiness is achieved unconditionally, naturalness is reproduced and the natural becomes artifical has been observed.
\end{abstract}

Keywords: New Media, Identity, Virtual Identity, YouTuber Identity. 


\section{Giriş}

Günlük yaşamımızın ayrılmaz bir parçası haline gelen yeni iletişim teknolojileri, toplumsal bağlamda yeni örüntüleri ve değișimleri de beraberinde getirmiștir. Sosyolojik açıdan yaşanan en önemli değişimlerden biri kimlik ekseninde ortaya çıkmıştır. Bireyin öznel kendilik hissini ifaden eden kimlik, bireylerin diğerleri ile olan aynılıkları ve farklılıkları çerçevesinde şekillenmektedir. Dolayısıyla kimlik toplumsal olarak inşa edilen bir nitelik taşımaktadır. Bu çerçevede Web 2.0'ın keşfi ile hayatımıza giren sosyal medya platformları bir toplumsal etkinlik alanı olarak değerlendirildiğinde bu alanda bir kimlik inşa sürecinden söz edilebilmektedir.

Dijitalleșmiş ve ağlar oluşturmuş bütünlüğe dayalı yeni çoğul iletişim sisteminin temel özelliği, bütün kültürel ifade biçimleri ile prosesleri kapsaması ve aktarmasıdır (Castells, 2008, s.499). Yeni iletişim teknolojileri bağlamında şekillenen kültürel ifade biçimlerinden biri sanal kimliktir. Sanal kimlik, yeni medya ortamında yapıp ettiklerimiz ve bu ortamda kendimizi sunuş biçimimizle ortaya çıkan bir kimlik türüne işaret etmektedir. Bununla birlikte sanal kimlik, sosyal ağlar üzerinden gerçekleşen toplumsal ve kişisel ilişkilere dayalı olarak inşa edilmektedir. Yeni medya ortamında inşa edilen kimlik, kişinin gerçek kimliğinin bir uzantısı olabileceği gibi çok farklı da olabilmektedir. Dolayısıyla yeni medya ortamı kişiye olmadığı bir "ben" inşa etmesi ve varlık alanını siber-uzamda genişletmesi için olanak tanımaktadır.

YouTube, kullanıcılara sunduğu pek çok imkân çerçevesinde sanal kimlik inşasının büyük oranda gerçekleştiği bir sosyal medya platformudur. 'Kendini yayınla' sloganıyla kullanıcılara seslenen YouTube, ücretsiz bir şekilde kişiye kendi kanalını kurma ve yayın yapma olanağı sunmaktadır. Kanal kurarak düzenli bir şekilde içerik üreticisi olan kișiler ise YouTuber olarak adlandırılmaktadır. Dolayısıyla YouTube ortamında çeşitli konular hakkında içerik üretip yayın yapan kişiler YouTuber kimliği altında birleşmektedir.

Kimlik temsili ve kimlik inşası bağlamında bir sosyal medya platformu olan YouTube üzerine odaklanan bu çalışma, sanal kimlik meselesini üretilen içerik çerçevesinde Vlogger olarak da tanımlanan YouTuberlar ekseninde ele almaktadır. Çalışmada betimsel analiz yöntemi kullanılmaktadır. YouTuber kimliğini betimleyerek bu kimliğin bir haritasını çıkarmak çalışmanın temel amacıdır. Bu amaç doğrultusunda Socialblade verilerine göre Türkiye'de abone sayısı en yüksek iki YouTube kanalı ele alınmakta, analiz edilmekte ve YouTuber kimliği detaylı bir şekilde betimlenerek bu kimliğe ilişkin bir çerçeve sunulmaktadır.

\section{Yeni Medyada Kimlik ve İnşası}

Teknolojik tabanlı gelişmelerle birlikte sürekli gelișen ve değișen yapısıyla tüm dünyayı etkisi altına alan yapay bir iletişim ortamı doğmuștur. Bu iletişim ortamı, var olan medya yapısını etkileşime dayalı olarak sanal veriye dönüştürmüş; üretim, dağıtım ve paylaşımın bilgisayarlar üzerinden gerçekleștiği yeni bir yapıyı ortaya çıkarmıştır (Manovich, 2001, s.19). 'Yeni' olarak ifade edilen bu medya ortamı, kullanıcıların zaman ve mekân sınırlaması olmadan bağımsız bir șekilde etkileșimde bulunmalarına imkân tanıyan sanal bir dünya yaratmıştır.

Gelişen bilgisayar, internet ve mobil teknolojileri ile birlikte ortaya çıkan sosyal ağlar zamanla gündelik yaşam pratiklerimizin önemli bir parçası haline gelmiştir. Sosyal paylaşım ağları, bireylerin kendi profillerini yarattıkları, zaman ve mekân sınırlandırması 
olmaksızın diğer kullanıcıların profilleri ile bağlantıya geçerek etkileşime girebildikleri sanal bir sosyalleşme aracı olarak tanımlanmaktadır.

Sosyal ağlar, kullanıcıların etkileșime dayalı olarak sosyal sanal gruplarda var olmalarını sağlamanın yanında sanal kimlik oluşturmalarına da imkân tanıyan bir medya ortamı yaratmaktadır. Diğer bir ifadeyle sanal ortam, kullanıcılara çeşitli amaçlarla gerçek kimliklerinin dışında yeni bir kimlik inşa etme imkânı tanımaktadır. Kullanıcılara gizlilik ve anonimlik de sağlayan sosyal paylaşım platformlarında bireyler, gerçek kimlikleri ile sergileyemeyeceği tutum ve davranışları yaratılmış olan sanal kimlikler üzerinden gerçekleştirebilmektedir. Dolayısıyla bu platformlarında, gerçek kimlikler ile sanal kimliklere dayalı tutum ve davranışlarda ciddi farklılıklar söz konusu olabilmektedir.

Kimlik kavramı zaman içinde tüm iç ve dış etkenlere bağlı olarak şekillenmekle birlikte kişide kalıcı olan aynılığı ifade etmektedir. Bu anlamda kimlik, bireyin öznel kendilik hissini tanımlamaktadır. Kimlik, kendi kültürel bağlamı içinde bireylerin diğerleri ile olan benzerlikleri ve farklılıklarından doğmaktadır. Dolayısıyla kimliğin şekillenmesinde bireyin diğerleri ile olan ilişki veya iletişimindeki eylem ve söylem pratikleri bir referans noktası olarak görülmektedir. Kimlik inşası kültürel açıdan; cinsiyet kimliği, etnik kimlik ve sınıf kimliği gibi farklı kategorilere dayalı çeşitlilik içermektedir (Chandler ve Munday, 2018, s.236). Farklı kimliklerin ortaya çlkmasında kimliklerin ötekine göre konumlandırılması etkili olmaktadır. Kimliğin ortaya çıkması ise bir süreç olarak görülmektedir. Bu süreç kimliğin bir defalığına gerçekleşen, an olmaktan ziyade sürekliliğe dayalı bir üretimini ifade etmektedir (Hall, 1998, s.70-72). Dolayısıyla kimliksel çeşitlilik sosyal alanda farklı etkenlere bağlı olarak ortaya çıkmakta, özellikle sosyal ağlarda farklı kimlik yapılandırmaları söz konusu olmaktadır. Bu çeşitliliği ortaya çıkaran birey kimliklerinin veya kimlik anlayışlarının şekillenmesi, bir süreç olarak görülmektedir. Kimliğin inşasını tanımlayan bu süreç, bireysel ve toplumsal ilişkilere dayalı olma özelliği taşımaktadır. Diğer yandan kullanıcılar sosyal ağlarda gerçek kimliklerinin dışında farklı kimliklere bürünebilmektedir.

Kimliklerin sosyolojik olarak bir inşa sürecinin sonucunda ortaya çıktığı geniş kabul gören bir görüştür. Ancak bu inşa sürecinin detayları tartışmaya açıktır. Öyle ki kimliklerin nasıl, nereden hareketle, kim tarafından ve ne için üretildiği gibi kimliğe ilişkin noktalar kimliğe dair önemli tartışma alanlarını olușturmaktadır (Castells, 2013, s.14). Diğer yandan kimlik kavramı farklı konu ve alanlara kayan anlamlar taşımaktadır. Bu açıdan kimlik, çeșitli tartışma zeminlerinde ele alınmaktadır (Kellner, 2013, s.218). Kimlik kavramı benlik, özne, kişilik gibi kavramlarla her düzeyde iç içe girmiş ve bu durum kimliğe ilişkin bir görüş bulanıklığı yaratmıştır (Hunt, 2018, s.107). Bu yönüyle uzlaşıya dayalı kavramsal bir tanımlamanın söz konusu olmadığı kimlik; sosyoloji, psikoloji ve felsefe gibi alanlarda farklı perspektiflerden ele alınmaktadır. Dolayısıyla kimlik kavramına yönelik çeşitli yaklaşımlar bulunmakta ve buna bağlı olarak kimliğe dönük farklı tanımlamalara rastlanmaktadır.

Sosyal alan, kimlik sınıflandırmalarının yanı sıra yeni kimliklerin oluşumuna da zemin oluşturmaktadır. Sosyal alanda gerçekleşen kimlik inşa sürecinde ise yerleşik toplumsal normlar ve iktidar önemli bir parametre olarak görülmektedir. Kimliğin ortaya çıkmasında kültür ve dil birlikteliği bağlamında siyasal ve etnik ortak yaşam alanlarının birlikteliğine dayalı "içerme"nin yanı sıra coğrafi, kültürel sınırlar düzleminde yaşama ilişkin belli simge ve semboller ile davranış kalıpları yaratılmasına dayalı olarak bir kimliğin başka bir kimliğe göre tanımlandığı "dışlama" etkili olmaktadır (Morley ve 
Robins, 1997, s.74). Kültürün doğasını yansıtan kültürel simgeler, kimliğin inşası veya yapılandırılması sürecinde önemli işlevler taşımaktadır. Diğer yandan medya kültürü, çeşitli içeriklerle içerme ve dişlamalar yaratarak kimliğin inşasına önemli kaynaklar ve katkılar sunmaktadır (Kellner, 2013, s.241). Bu açıdan medya kültürü yarattığı içerme ve dişlamalar ile "biz" ve "onlar" kategorileri yaratmakta, bu yönüyle de gerek sosyal alanda gerekse sosyal ağlarda kimlik inşasında etkili bir rol oynamaktadır. Bununla birlikte sosyal medya, yerleşik toplumsal norm ve iktidar gibi parametrelerin etkisiyle kullanıcıların gerçek yaşamda kullanamayacakları veya kullanmakta zorlanacakları kimlikleri yeniden inşa ederek bu kimlikleri sanal bir düzlemde yaşadıkları/yaşattıkları bir alana dönüşmektedir.

Toplumsal normlar üzerinden şekillenen "biz" ve "onlar" kategorizasyonu, kimliksel farklılıklar ortaya koyan tutum, davranış, duygusal bağlar, antipati, güven, duygu, korku, işbirliği ve çekişme gibi temsiller taşımaktadır. Dolayısıyla bu temsiller üzerinden birey aidiyet duygusuna dayalı olarak "biz" kategorisi içinde yer alır. "Onlar" kategorisi ise haklarında çok fazla şey bilinmeyen, korkutucu ve kestirilemez davranışlar beklenen grupları temsil eden ve bireyin ait olmadığı, ait olmak istemeyeceği grupları tanımlamaktadır (Bauman, 2013, s.51). Bu kategoriler bireyin içinde yaşadığı sosyal alandaki ilişkiler ağını ortaya koymakla birlikte bireyin dıș dünyaya dönük davranışlarının da belirleyicisi olma özelliği göstermektedir.

"Biz" ve "onlar" kategorizasyonu içinde şekillenen kimliğin inşasında "iyi" özelliklerden oluşan gruplar kategorik olarak "biz"i oluşturmaktadır. Bunun dıșında kalan ve "kötü" özelliklerle tanımlanan gruplar ise "onlar" kategorisini oluşturmaktadır. Dolayısıyla "Kimliğin zihinsel üretimi”ni ifade eden bu süreç kimlikler arasında keskin bir çizgi oluşturmaktadır. Bu keskin çizgi, iki kimlik arasında bir çatışma doğurabilmektedir (Baumann, 2013, s.52). Kimliklerin inşa sürecinde etkili bir role sahip olan medya ise kimliksel çatışmaları derinleştirebilmektedir.

Dünyada kimlikler üzerinden tehlikeli çatıșmaların yaşandığını savunan Bayart'a göre bu çatışmalar, kültürel kimliğin siyasal bir kimliğe denk düştüğü varsayımına dayanmaktadır. Ancak Bayart bu kimliksel çatışmayı yanılsama olarak görmekte ve kimliklerin her birini "olsa olsa kültürel bir inşa, siyasal veya ideolojik bir inşa" olarak tanımlamaktadır. Dolayısıyla kimlik, başlı başına tarihsel bir inşa olma özelliği taşımaktadır (1999, s. 9). Castells'e göre ise kimlik inşası tarih, coğrafya, biyoloji, üretken ve üremeye yönelik kurumlar, kolektif hafıza, kişisel fanteziler, iktidar aygıtları ve dini vahiyler gibi çeşitli unsurlar üzerinden gerçekleşmektedir. Kimliğin ortaya çıkmasında etkili olan bu unsurlar bireyin içinde yaşadığı toplumsal koşullar ve kültürel projelere göre işlenmekte, iktidar ilişkilerinin de etkisi ile kimliğe dair anlamlar yaratılmaktadır. Kimliğe ilişkin tüm bu süreç, uzam-zaman bağlamında teknolojinin gelişimini de içine alan çok yönlü bir yapı içinde şekillenmektedir (Castells, 2013, s.14). Diğer yandan teknolojik gelişmeler sosyal alanda birçok değişikliği beraberinde getirmiştir. Bu alanlardan biri de toplumsallaşma sürecidir. Sanal dünya, kullanıcıların kendilerini yeniden konumlandırdıkları bir sosyal alan olma özelliği kazanmıştır. Dolayısıyla kullanıcılar sanal dünyada toplumsal sermayelerini de yeniden inşa etme çabasına girişmekte, bu çaba yeni bir kimlik inşasını doğurmaktadır (Binark ve Bayraktutan, 2008). Bu durum özellikle sosyal ağlarda kimliklerin sanal bir düzleme oturmasında etkili olmakta ve sanal kimliklerin inşasını ortaya çıkarmaktadır. 


\section{Sanal Kimlikler}

Bilgisayar teknolojileri, enformasyonun bir araya getirilip işlenmesi, aktarımı ve depolanmasını son derece kolaylaştırarak enformasyonun küresel anlık paylaşımını mümkün kılmıştır. Devrimsel nitelikteki teknolojik gelişmeler zinciri beraberinde bilgisayar ve internet teknolojilerini yaygınlaștırmış ve kullanım alanını genişletmiștir. Dolayısıyla bu ağ yapılanmalarının sadece kişiler arası değil toplumlar arası etkileşime de güçlü yansımaları olmuştur.

A $\breve{g}$ teknolojilerinin yarattığı ve hızın ön planda olduğu bu yapının doğurduğu makro dönüşüm süreci, mikro mühendislik çalışmaları düzleminde küresel çapta sayısal teknolojiler, internet ve bilgisayar kullanımının yaygınlaşmasının yanı sıra dijital bölünme gibi farklı açllardan ele alınabilecek güçlü etkiler yaratmıştır (Castells, 2008, s.171). Özellikle Web 2.0'a uzanan web teknolojilerinin gelişimi ve etkileşim temelli sosyal ağların ortaya çıkışıyla birlikte gündelik sosyal ilişkilerin dahi bu ağlar üzerinden gerçekleştiği toplumsal bir yapı söz konusu olmuştur. İletişim süreçlerinin dijitalleşmesini ifade eden bu gelişmeler, toplumsal ilişkilerin sanal bağlar/ağlar üzerinden yürüdüğü bir siber uzam olarak ifade edilmektedir.

Sosyal ağlar ve bu ağlar üzerinden gelişen kişisel ve toplumsal ilişki biçimi interdisipliner yapısıyla farklı alanlarda farklı perspektiflerden ele alınan geniş çaplı bir tartışma konusu olmuştur. Sosyal ağlar, günümüzde dünyanın en güçlü çevrimiçi medyası olma özelliği taşımaktadır. Bu yönüyle gündelik yaşamın vazgeçilmezi haline gelen sosyal ağlar, kimlik yapılandırmaları açısından önemli bir yer tutmaktadır. Bu bağlamda sosyal ağlar, gerçek yaşamda gerçek kimliklerin dışında yapılandırılmış bir kimlik yaratımına zemin oluşturmaktadır.

Yeni iletişim teknolojileri, kimlik yapılandırmaları noktasında kullanıcılara geniş bir hareket alanı sunmaktadır. Bu teknolojiler kullanıcılara biyografilerini, kimliklerini ve benliklerini yeniden inşa etme imkânı sağlamaktadır (Morva, 2014). Bununla birlikte internet ortamında sosyal mekânın sınırı bulunmamaktadır. İnternette mekân, tek bir ortamı değil aynı anda birden fazla ortamı içine almaktadır. Bir sosyalleşme alanı olan sanal mekânlar yan yana, ard arda ve iç içe pencerelerden oluşmaktadır. Bu pencereler kullanıcıları sosyal, duygusal ve zihinsel gereksinimleri karşılayan, simülasyon olarak ifade edilebilecek etkileşime dayalı bir gerçeklik boyutuna taşımaktadır (Armağan, 2013). Kullanıcılar bu boyutta yeni bir gerçekliğe dayalı olarak tasarladıkları sanal kimlikleri ile var olmaktadır. Sosyal ilişkilerde kullanılan ve bu yönüyle sosyal bir kimlik olan sanal kimlik, kullanıcıların sanal dünyada kullandığı yaratılmış bir kalıp olma özelliği taşımaktadır. İnternetin zaman ve mekân sınırı olmaksızın sunduğu erişim, tercih ve anonimlik gibi özellikleri çerçevesinde kullanıcıların kim olmak istedikleri konusundaki tutumları, sanal kimliğin inşasında önemli parametreleri oluşturmaktadır.

Kimliğin yaratım sürecinde önemli işlevlere sahip olan enformasyon miktarı ve niteliğinin kontrol edilebilirliği çerçevesinde gerçek kimliğe ilişkin bilgilerin gizliliği sağlanırken, anonim olan sanal kimliğe ilişkin bilgiler ise herkese açıtır (Timisi, 2005, s. 96). Kimliğin inşasında erişim, tercih ve anonimlik, kullanıcıların gerçek kimlikleri ile sanal kimlikleri arasında tutum ve davranış farkı oluşturmaktadır. Bu farklılığı ortaya koyan sanal kimlikler, kullanıcıların gerçek kimliklerinin dışında çeşitli gerekçe ve etkenlerle inşa ettikleri idealize kimliklerdir. Dolayısıyla sanal kimlik kavramı, kullanıcıların olmak istedikleri sanal sosyal kimlikleri ifade etmektedir. 
Sosyal ağlar kullanıcıların farklı isim, fotoğraf, davranış biçimi ve kimliklerle var oldukları, dolayısıyla kendileri hakkında izlenim yarattıkları mecralar olarak kullanılmaya başlanmıştır. Bu hususlar günümüzde kimlik yönetiminin en yaygın örnekleri arasında gösterilmektedir. Ayrıca internet ortamında kimlikler sabit olmaktan çıkarak değişken ve akışkan olma özelliği kazanmıştır (Timisi, 2005, s.96-97). Kullanıcıların sanal mecrada tasarladıkları sanal kimlikler, kimlik yönetimi çerçevesinde etkileşime dayalı olarak şekillenmekte ve sürekli değişime uğrayabilmektedir. Özellikle de abone/takipçi sayısı, beğeni sayısı ve yorumlar üzerinden beğenilme, takdir görme ve popülerlik gibi hususlar kimliğin inşasında ve inşa edilen kimliğin etkileșime dayalı olarak şekillendirilmesinde önemli etkenler arasında yer almaktadır.

\section{YouTube}

YouTube, 2005 yılında Steve Chen ve Chad Hurley tarafindan kurulan ve sonrasında Google tarafından satın alınarak geliștirilen bir video paylaşım platformudur. 'Kendini yayınla' mottosuyla kullanıcılarına seslenen YouTube, basit bir paylaşım sitesi olmanın ötesinde kullanıcılara kendi kanalını kurma ve yayın yapma imkânı da tanımaktadır. Farklı dil seçeneklerinin yanı sıra kullanışlı bir arayüze sahip olan YouTube, kullanılabilirlik politikalarını kullanıcı talepleri üzerinden yürütmektedir (Burgess ve Green, 2009, s.65-66).

İnteraktif içerik üretim platformu olma özelliği taşıyan YouTube, kullanıcılara yorum yapma, anlık hikâye paylaşımı, canlı yayın yapma gibi özellikler de sunmaktadır. $\mathrm{Bu}$ özellikleri açısından YouTube, web. 2.0 fenomeninin önemli bir parçası olarak görülmektedir (Miller, 2012, s.17). Diğer taraftan yüklenme tarihi, izlenme, beğeni (like) ve beğenilmeme (dislike) sayıları paylaşılan videonun hemen altında görülebilmektedir. YouTube üzerinden yayın yapan bir kanal 'hakkında' bölümünde kanalın kuruluş amacı ve ne gibi içerikler üreteceğine ilişkin açıklamalarda bulunabilmekte, paylaşılan videoların altına açıklama ekleyebilmekte ve oynatma listeleri oluşturabilmektedir. Ayrıca hiperlinkler aracılığıyla sosyal ağların birbirine bağlanması, YouTube videolarının istenilen sosyal paylaşım platformlarında kolayca paylaşılmasını mümkün kılmaktadır.

YouTube, içerik üreterek kullanıcılara sunmak yerine içerik üretmeye imkân tanımış ve üretilen içeriğin yönetimini de kullanıcılara bırakarak küresel bir platform olmuştur. İnternete dayalı kitle iletişimin metalaştırılmasına dönük yollar arayan YouTube, kullanıcılara daha güçlü hitap edebilmek için etkileyici özellikler sunmakta, yapısını sürekli geliștirmektedir (Castells, 2009 s.97, 129-130). Bu yönüyle Web 2.0 teknolojisi temelinde yayın yapan YouTube sıradan kullanıcının aktif, etkileşimli ve medyatik hale gelmesine imkan sağlamıştır. Sıradan bir sosyal medya kullanıcısı ilgi alanı, hobileri ve becerileri doğrultusunda kanal açıp yayın yapabilmektedir. Yemek tarifinden, makyaj videolarına, diyet tariflerinden, oyun videoları ve film analizlerine kadar çok çeşitli içerikler üreten sayısız YouTube kanalı mevcuttur. Bu açıdan kültürel bir sistem olarak YouTube'un amaçları ve anlamları kullanıcıların ortak katılımıyla yaratılmaktadır (Burgess ve Green, 2009, s.61).

YouTube'da geleneksel medyaya göre çok daha çeşitli ve zengin içeriklere ulaşlabilmektedir. Diğer taraftan YouTube'un zamanla daha popüler hale gelmesi geleneksel medya organlarının bu platform üzerinden yayın yapmasının önünü açmış, geleneksel medya ile ünlenen pek çok kişinin yayınlarını bu platform aracılığıyla yapmasına neden olmuştur. Örneğin; bir televizyon kanalında uzun yıllar yayın yapan Beyazıt Öztürk, bir TV programının sunuculuğunu yapan Çağla Şikel YouTube aracılığıyla 
yayın yapmaktadır. Diğer taraftan YouTube dizileri ortaya çıkmış ve YouTube aracılığıyla yayın yapan pek çok kişi geleneksel medyada görünür hale gelmiştir.

YouTube'da geleneksel medyada yer edinemeyen milyonlarca kişi para kazanmak, görünür olmak ya da geleneksel medyada göremediğimiz alternatif içerikler üretmek için yayın yapmaktadır. Örneğin; geleneksel haber kanallarına alternatif olarak 2019 Ağustos ayında 'Babıali TV' kurulmuştur. 'Babıali TV' ilk YouTube haber kanalıdır. Diğger taraftan pek çok farklı ülkeden yayın yapan kanallara ulaşmak ise oldukça kolaydır. YouTube küresel ölçekte bir sosyal paylaşım ağı olarak değerlendirildiğinde kültür taşıyıcılığına hizmet ettiği de görülmektedir. Örneğin; Liziqi adıyla yayın yapan ve 7 milyondan fazla kullanıcısı olan bir YouTube kanalı Çin yemeği ve kültürüne ilişkin içerikleri ile dikkat çekmektedir.

Bir YouTube videosu ortalama 10 dakikadan, bir açılış veya kapanış jeneriğinden, kanal sahibinin konuşmaları ve yapıp ettiklerinden oluşmaktadır. YouTube kanalı açıp sürekliliği olacak șekilde yayın yapan kişiler YouTuber olarak adlandırılmaktadır. Farklı yayın anlayışları, çekim teknikleri ve konular ile gördüğümüz içerik üreticileri YouTuber tanımı altında birleşmektedir. Fakat YouTuber, sosyal ağlar için içerik üreten kişi olmanın ötesinde bir kimlik temsiline işaret etmektedir. Diğer bir deyişle YouTuber, içerik üretmenin yanında kimliğe ilişkin belirli temsiller de üretmektedir.

\section{Yöntem}

Bu çalışma popüler bir sosyal medya platformu olan YouTube ortamına ve Yotuber'lara odaklanmaktadır. Çalışmanın temel amacı sanal kimlik inşasını YouTuberlar özelinde değerlendirmek ve YouTuber kimliğini betimleyerek bu kimliğe ilişkin bir harita çıkarmaktır.

Çalışma kapsamında YouTuberların kimlik temsiline ilişkin betimsel bir analiz yapılmaktadır. Betimsel analiz, daha önceden belirlenmiş temalar doğrultusunda elde edilen verilerin özetlenmesi ve yorumlanmasını içermektedir. Betimsel analizde temel amaç elde edilmiş bulguların sistematik ve yorumlanmış bir biçimde okuyucuya sunulmasıdır. $\mathrm{Bu}$ analiz türünde elde edilen veriler düzenli ve açık bir biçimde betimlenmekte, yorumlanmakta, neden-sonuç ilişkisi irdelenmekte ve böylece birtakım sonuçlara ulaşılmaktadır (Yıldırım ve Şimşek, 2018, s.239-240).

Socialblade verilerine göre Türkiye'de abone sayısı en yüksek iki kişisel YouTube kanalı örneklem olarak seçilmiştir. Bu kanallar Orkun Işıtmak ve Enes Batur'un kendi isimleri ile açtıkları YouTube kanallarıdır. Çalışmada ele alınan video kanalları detaylı bir şekilde incelenmiş, kimlik inşası bağlamında analiz edilmiștir. Bu analizler, kanalların ilk dönem ve son dönem videolarından birer örneğin seçilmesiyle detaylandırılmıştır. Bu kapsamda Orkun Işıtmak'ın “ILLK VLOG! - Duyurular, Gelen Sorular, Oynanacak Oyunlar - Cumartesi BLOGU” başlıklı, 38.158 görüntüleme alan 12 Ekim 2019 tarihinde yayınladığı video ile “ÖZEL BİSİKLETLER İLE DRİFT YARIŞI! (KAZA YAPTIM!)” başlıklı, 1.089.165 görüntüleme alan 5 Ekim 2019 tarihli videosu ele alınmıştır. Enes Batur'un ise ilk dönem videolarından, 208.310 görüntüleme alan "VLOG - Fırat ve Enes Soru Cevaplıyoruz" başlıklı 30 Ağustos 2014 tarihli videosu ile "24 SAAT BOYUNCA TEK RENK CHALLENGE” başlıklı, 11 Ekim 2019'da yayınlanan ve 6.772.006 görüntüleme alan videosu ele alınmıștır.

\section{Analiz}

Çalışma kapsamında ele alınan YouTuberlardan ilki Orkun Işıtmak'tır, Tablo 1'de gösterildiği üzere kendi ismi ile Nisan 2010'da eğlence kategorisinde açtığı ve 
doğrulanmış (onaylı) YouTube kanalı, Kasım 2019 itibariyle 1 milyar 600 milyondan fazla görüntüleme, 6,5 milyonun üzerinde abone, 1200'den fazla videonun yanı sıra toplamda 1 buçuk milyarın üzerinde izlenme istatistiklerine sahiptir. Orkun Işıtmak, eğlence ve oyun içerikli videoları ile dikkat çekmektedir. 2012 yılında "Orkun Işıtmak 2" adıyla kurduğu ikinci bir YouTube kanalına sahip olan YouTuber, bu kanalda ise özel hayatını paylaştığı günlük video blog (vlog)'lar ile diğer eğlenceli videolar ve kamera arkası görüntülerini yayınlamaktadır.

Tablo 1: Orkun Işıtmak YouTube Kanalına İlişkin İstatistiki Veriler

\begin{tabular}{|l|l|l|l|l|}
\hline Video Sayısı & Abone Sayısı & Video İzlenme Sayısı & Kuruluş Tarihi & Kategori \\
\hline 1273 & $6.88 \mathrm{M}$ & $1,683,403,229$ & 18 Nisan 2010 & Eğlence \\
\hline
\end{tabular}

Orkun Işıtmak YouTube kanalını 2010 yılında kursa da ilk oyun videosunu "Orkun - Left 4 Dead 2 Multiplayer Oynarken - Part 1" adıyla 19 Temmuz 2012'de yayınlamıștır. Bunun öncesinde 2010 yılında iskambil kâğıtları ile yapılan kısa süreli birkaç gösteri videosu da bulunmaktadır. Vlog niteliğindeki ilk videosunu ise 12 Kasım 2012'de "ILK VLOG! Duyurular, Gelen Sorular, Oynanacak Oyunlar - Cumartesi BLOGU" adıyla yayınlamıștır.

Türkiye'de en çok aboneye sahip üçüncü YouTube kanalı olan Orkun Işıtmak'a ilişkin Tablo 2'de gösterilen Soialblade verilerine göre kanalda günlük, haftalık ve aylık rutin pozitif abone ve izleyici sayısı artışı gözlenmektedir. Bu verilerden hareketle yıllık abone ve video izlenme sayılarında pozitif yönde beklenti oluşmuştur.

Tablo 2: Orkun Işıtmak YouTube Kanalına İlişkin İstatistiki Veriler ("Socialblade", t.y.)

\begin{tabular}{|l|l|l|}
\hline & Abone Sayısı & Video İzlenme Sayısı \\
\hline Günlük Ortalama & +334 & +485.780 \\
\hline Haftalık Ortalama & +2.330 & $+3.400,460$ \\
\hline Son 30 Gün & +10.000 & $+14.573,395$ \\
\hline Yıllık Tahmin & +120.000 & $+174.880,740$ \\
\hline
\end{tabular}

2018 yılında 'İyi Oyun' adlı sinema filminde oynayan Orkun Işıtmak, aynı yıl 45.'si düzenlenen Altın Kelebek Ödüllerinde En iyi YouTuber ödülünü almıştır. Orkun Işıtmak, kendisini vlogger olarak tanımlamaktadır. Kanalında abonelik butonunun üstünde de "Vlog kanalıma abone olun!” yazmaktadır. YouTube kanalında kişisel web sitesinin yanı sıra Facebook, Twitter ve Instagram hesaplarına bağlantı verildiği görülmektedir. Kanalın kapak fotoğrafında maceracı yönünü yansıtan, çizime dayalı bir görsel göze çarparken profil kutucuğunda özgüvene vurgu yapan bir fotoğraf kullanılmıștır.

YouTube'da içerik üretmeye başladığı ilk yıllarda videolarının büyük bir bölümü bilgisayar oyunları üzerine olan Orkun Işıtmak, zamanla eğlence videolarına ağırlık vermeye başlamıştır. Gezi, şaka, sosyal deney gibi farklı kategorilerde videolar çeken Orkun Işıtmak ayrıca son zamanlarda YouTuberlar arasında popüler olmaya başlayan albüm çıkarma furyası içinde yer alarak "Gündönümü” adında bir albüm çıkarmıştır.

Orkun Işıtmak'ın YouTube kanalında en popüler videoları 3 milyon ile 35 milyon arsında görüntülemeye ulaşmıştır. Orkun Işıtmak videolarında geleneksel yayıncılık anlayışının tam tersine jeneriksiz başlangıç yapılmaktadır. Birçok videonun başında sosyal medya hesapları arasından sadece Instagram hesabını gördügümüz videoların yanı sıra ünlüler veya sosyal medya fenomenleri ile çekilen videolarda diğer kişilerin Instagram hesaplarının da video başlangıcında verildiği görülmektedir. 


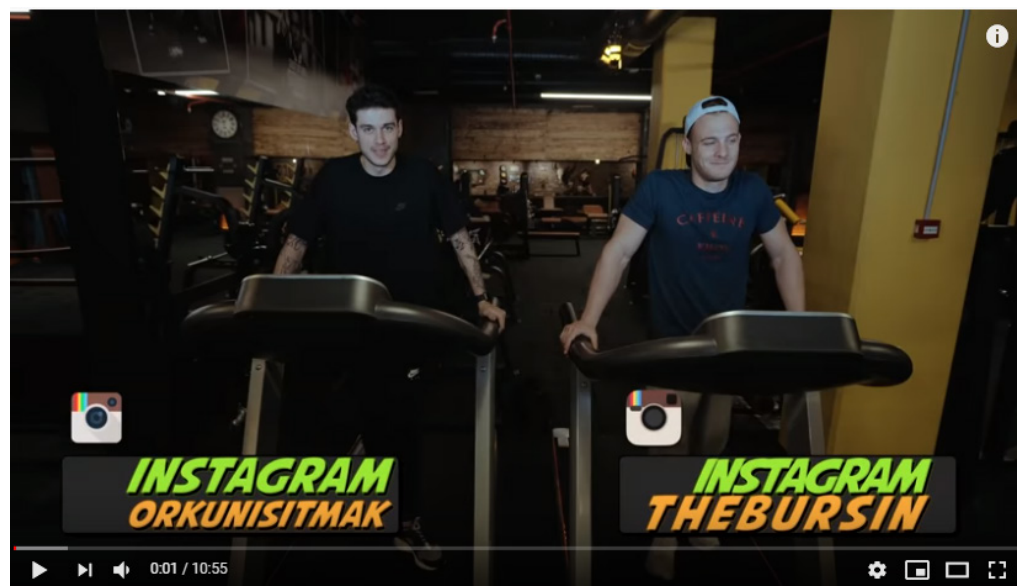

Şekil 1: Orkun Işıtmak YouTube Kanalındaki Örnek Video Başlangıcı.

Orkun Işıtmak oyun videoları dışındaki eğlence videolarını genellikle farklı mekânlarda çekmektedir. Videolarında son derece dinamik konuşan YouTuber, sempatik tavırlar sergilemektedir. Merak uyandırıcı video başlıklarının kullanıldığı videolarının bazılarında farklı marka ve alışveriş sitelerinde kullanılmak üzere abonelerine indirim kodu uygulaması söz konusudur. Bu yönüyle Orkun Işıtmak, markalarla sponsorlu ortaklıklar kurarak üretilen içerikler ve video açıklamalarında reklam ve tanıtım unsurlarını kullanmaktadır.
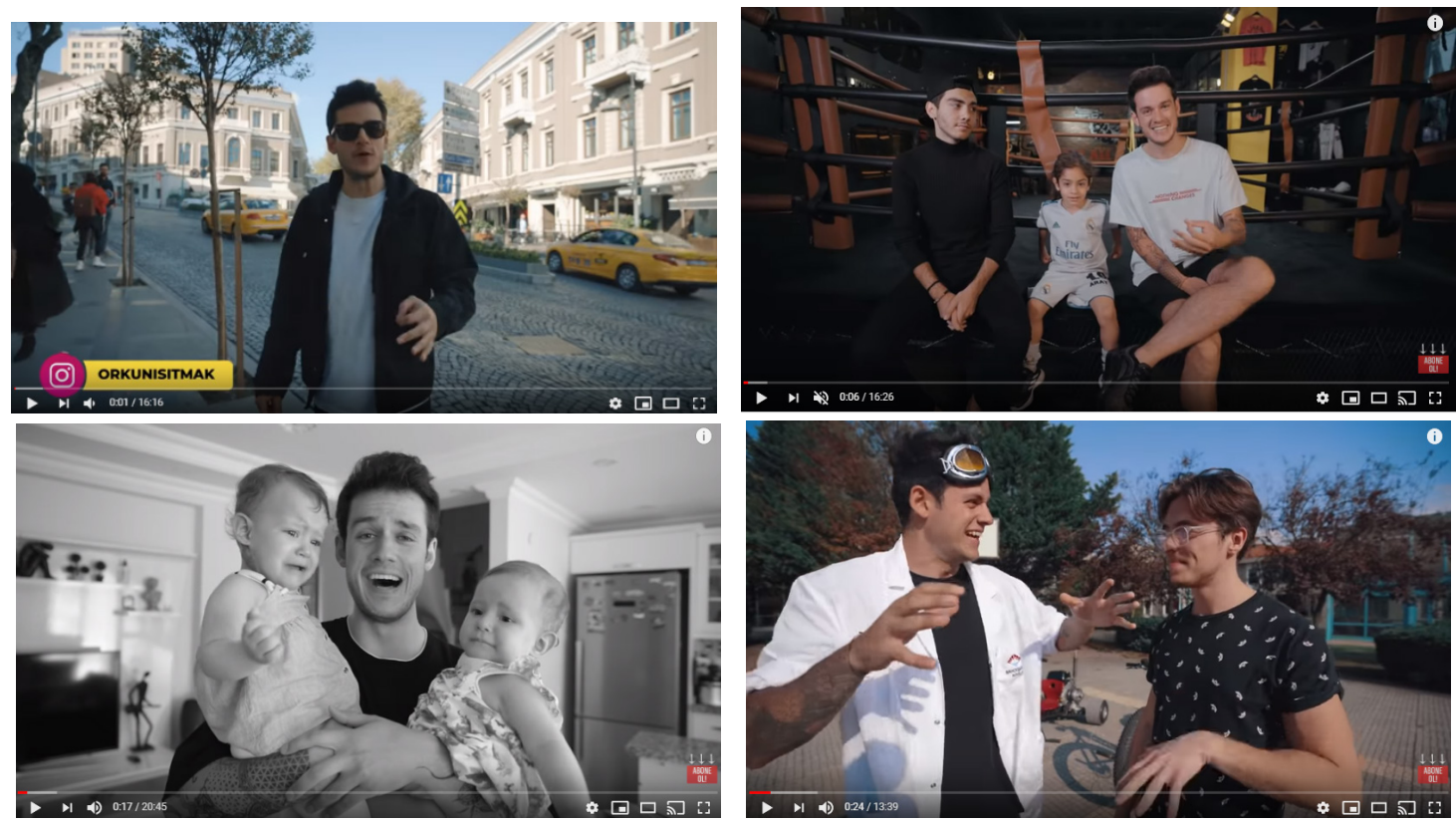

Şekil 2: Farklı Mekânlarda Çekilen Videolardan Örnekler.

Orkun Işıtmak videolarının süreleri özellikle son yıllarda ortalama 10 dakikanın üzerinde olmakla birlikte 20 dakikayı aşan videoları da bulunmaktadır. Ancak ilk yıllardaki videolarının daha kısa olduğu görülmektedir. Ayrıca ilk dönem videoları ile son dönem videoları arasında gerek teknik gerekse içerik olarak büyük farklılıklar bulunmaktadır. Aktif içerik üretiminin gerçekleștiği 7 yıllık periyotta kanal profesyonelleşme eğilimi göstermiş, Orkun Işıtmak kamera önünde büyümüştür. İlk yıllarda daha çok çocuklara hitap eden içerikler, sonraki yıllarda gençlere hitap eden bir yapıya dönüşmüştür.

Söz konusu kanalda 1273 videonun tamamının incelenmesi çalışma sınırlılıkları gereği mümkün olmamakla birlikte 2010 yılında kurulan kanalın zamanla geçirdiği dönüşümü daha iyi görmek ve YouTuber'ın kimlik temsiline ilişkin daha detaylı bir analiz yapmak 
amacıyla ilk vlogun yayınlandığı 2012 yılından ve 2019 yılındaki son güncel videoları arasından olmak üzere birer video incelenmiştir. Bu videolar incelenirken kullanıcı yorumları da dikkate alınmıştır. Böylece Orkun Işıtmak tarafından yaratılan kimlik temsilinin izleyicide nasıl bir karşılık bulduğu da ortaya konulmaya çalışılmıştır.

Analiz çerçevesinde ele alınan ilk video, 2012 yılına ait bilgisayar oyunları ile ilgili "ILLK VLOG! - Duyurular, Gelen Sorular, Oynanacak Oyunlar - Cumartesi BLOGU" başlıklı videodur. 38 binin üzerinde bir izlenme oranına sahip olan video, başlığında yazıldığı gibi Orkun Işıtmak'ın ilk vlog çalışmasıdır. 10 dakikalık bu video abonelerden gelen sorular üzerine YouTuber tarafından verilen cevaplarla başlamaktadır. Çok yüksek konfigürasyona sahip bir ekipmanının olmadığını belirten Orkun Işıtmak, videoyu ev ortamında, bilgisayar başında çekmiştir. Yavaş ve akışkan olmayan video, çözünürlük açısından da çok iyi değildir. 185 yorumun yapıldığı videoda eski yorumlar oyunlara ilişkinken güncel yorumlar Orkun Işıtmak'ın birçok açıdan yaşadığı değişime vurgu yapmaktadır.

Çalışmada Orkun Işıtmak'ın incelenen ikinci videosu ise “Özel Bisikletler İle Drift Yarışı! (Kaza Yaptım!)” başlıklı, 1 milyondan fazla görüntülemeye ulaşan 5 Ekim 2019 tarihli videodur. Kısa süre içinde 3. Binden fazla yorum alan ve süresi 13:39 olan videoda Orkun Işıtmak, kendisi tarafından tasarlandıktan sonra özel olarak yaptırılan motorlu bisikletler ile yaptığı yarış deneyimini abonelerine aktarmaktadır. Birden fazla kamera, müzik, farklı açı ve kadrajlar ile dinamik bir kurgunun dikkat çektiği video heyecan verici senaryolarla hem eğlenceli hem de merak uyandırıcı hale getirilmiştir.

Ele alınan her iki video karşılaştırıldığında Orkun Işıtmak'ın ortaya koyduğu yükselen YouTuber imajı özendirici bir nitelik taşımaktadır. Yorumlarda Orkun Işıtmak'ın aboneleri tarafından hayranlık duyulan biri olduğu anlaşılmaktadır. Bununla birlikte izleyici yorumlarında YouTuberın yaşam tarzına duyulan hayranlık ve bu yaşam tarzına ulaşamayacak olmanın verdiği hayal kırıklığı dikkat çekmektedir. Kullanıcılar YouTuberın yaşamının tüm ayrıntılarını merak etmekte ve YouTubera bu konularda pek çok soru yöneltmektedir. Ayrıca YouTuberın video içeriklerinin şekillenmesinde kullanıcı talepleri etkili olmaktadır.

Videolar üzerinden inşa edilen kimlik, gündelik yaşamda ekonomik sorunlar başta olmak üzere karşılaşılan çeşitli zorluklar ve sorunlardan uzak, eğlenceye dayalı, her istenilenin kolayca yapılabildiği temsile karşılık gelmektedir. Şöhrete dayalı olarak gerçekleşen kimlik inşasının yanında 'bizden biri' olma imajı üzerinden YouTube fenomeni veya YouTuber/Vlogger olarak tanımlanan kişiler, geleneksel medyada yer alan "ünlü" statüsünün ötesinde bir karşılık bulmaktadır.

Orkun Işıtmak'ın YouTube videoları üzerinden yarattı̆̆ı YouTuber kimliği, abone sayılarının, izlenme oranlarının ve popülaritesinin artması ile pekişmektedir. Yaratılan bu kimlik maceraya açık, geniş bir arkadaş çevresine sahip ve dost canlısı olmasının yanında eğlenceli bir kişilik olarak eğlence odaklı bir hayat yaşayan, ekonomik sorun ve sıkıntılardan uzak bir kişi biçiminde inşa edilmektedir.

Çalışmada ele alınan ikinci YouTuber Enes Batur Sungurtekin'dir. Tablo 3'de gösterildiği üzere kendi adıyla Kasım 2012'de oyun kategorisinde açtığı doğrulanmıș (onaylı) YouTube kanalı Kasım 2019 itibariyle 1800'ün üzerinde video, 11 milyonun üzerinde abone, 5,5 milyardan fazla görüntüleme istatistiklerine sahiptir. Bilgisayar ve konsol oyunlarıyla ilgili inceleme videolarıyla tanınan Enes Batur, oyun başta olmak üzere eğlenceye dönük 
videoları ile dikkat çekmektedir. Orkun Işıtmak gibi Enes Batur da 'Enes Batur 2' adıyla ikinci YouTube kanalını açmıştır. 2013'de açılan ve Kasım 2019 itibariyle sadece 8 video bulunan bu kanalda abone sayısı ise 1 milyonu aşmıştır.

Tablo 3: Enes Batur YouTube Kanalına İlişkin İstatistiki Veriler.

\begin{tabular}{|l|l|l|l|l|}
\hline Video Sayısı & Abone Sayısı & Video İzlenme Sayısı & Kuruluş Tarihi & Kategori \\
\hline 1817 & $11.3 \mathrm{M}$ & $5,506,463,508$ & 18 Kasım 2012 & Oyun \\
\hline
\end{tabular}

YouTube kanalını 2012 yılında açan Enes Batur, ilk videosunu 20 Ocak 2013'de "MinecraftHunger Games (Açlık Oyunları) Enes Oynuyor Bölüm 1" başlığı ile yayınlamıştır. Enes Batur Vlog niteliğindeki ilk videosunu ise "VLOG - Firat ve Enes Soru Cevapliyoruz" başlığıyla 30 Ağu 2014'te yayınlamıştır.

Socialblade verilerine göre Enes Batur'un YouTube kanalı günlük, haftalık ve aylık rutin pozitif abone artışına sahiptir. Bu verilerden hareketle yıllık abone ve video izlenme sayılarında da pozitif yönde beklenti söz konusu olmuş ve analizlere yansımıștır. Bu istatistikler ve beklenti, Enes Batur'un yükselen imajının devamına işaret etmektedir.

Tablo 4: Enes Batur YouTube Kanalına İlişkin İstatistiki Veriler ("Socialblade," t.y.)

\begin{tabular}{|l|l|l|}
\hline & Abone Sayısı & Video İzlenme Sayısı \\
\hline Günlük Ortalama & $+3.33 \mathrm{Bin}$ & $+3,380,990$ \\
\hline Haftalık Ortalama & $+23.3 \mathrm{Bin}$ & $+23,666,930$ \\
\hline Son 30 Gün & +100.000 & $+101,429,674$ \\
\hline Yılık Tahmin & +1.2 Milyon & $+1,217,156,088$ \\
\hline
\end{tabular}

Enes Batur 2017 yılında 44. Altın Kelebek Ödüllerinde En iyi YouTuber ödülünü almış ancak bu ödül daha sonra kendisinden geri alınmıștır. 2018 yılında kendi hayatını anlatan 'Enes Batur Hayal mi Gerçek mi?' sinema filmi ile oyunculuğa soyunan Enes Batur'a, aynı yıl 5. Altın Palmiye Ödülleri'nde Yılın Sosyal Medya Fenomeni Ödülü verilmiştir. Diğer yandan Enes Batur'un ikinci filmi olan 'Enes Batur Gerçek Kahraman' ise 2019 yılında vizyona girmiștir. Türkiye'nin en büyük YouTube kanalı olduğunu vurgulayan Enes Batur, oyun videoları ile başlasa da farklı türlerde yayın yapabildiğini vurgulamaktadır.

Enes Batur YouTube kanalında, kişisel web site ile Instagram ve Twitter hesaplarına bağlantı verilmiştir. Kanalın kapak fotoğrafında yakın plan Enes Batur'un fotoğrafı ile birlikte “Türkiye’nin En Büyük YouTube Kanalı” yazısı yer almaktadır. "Çarşamba-CumaCumartesi 19:00 Yeni Video" ibaresi ile kanalın sürekliliği ve güncelliği vurgulanmaktadır.

YouTube'da 13 yaşından itibaren içerik üretmeye başlayan Enes Batur ilk yıllarda büyük oranda oyun inceleme videoları paylaşırken son yıllarda eğlence odaklı farklı videolarıyla dikkat çekmektedir. Eğlence, gezi ve şaka içerikli videoları ön planda olan Enes Batur, farklı YouTuberların yanı sıra Acun Ilıcalı ve Ali Koç gibi tanınmış isimlerin yer aldığı videolarla içeriği çeşitlendirerek kanalını daha da ilgi çekici hale getirmektedir. Ayrıca YouTuberlar arasında son zamanlarda popüler hale gelen müzik klipleri furyasına Enes Batur da dâhil olmuştur.

Enes Batur YouTube kanalında en popüler videolar 7 milyon ile 60 milyon arasında görüntüleme almıştır. Orkun Işıtmak videolarında olduğu gibi Enes Batur videolarında da jeneriksiz başlangıçlar dikkat çekmektedir. Enes Batur videolarının bazılarında sosyal medya hesapları verilse de birçok videoda sosyal medya hesapları da dâhil olmak üzere yazı öğesi kullanılmamaktadır. 

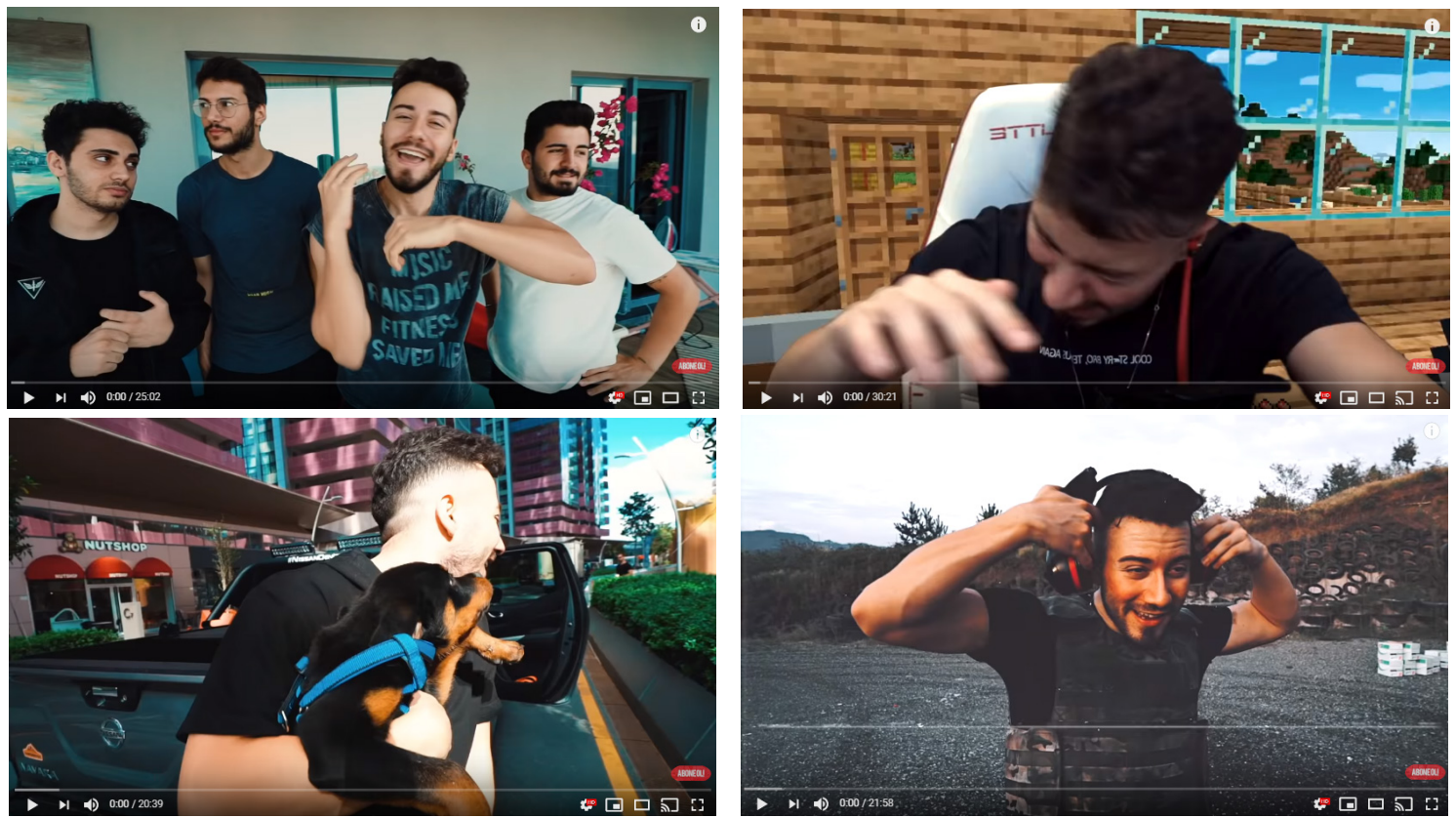

Şekil 3: Enes Batur Video Başlangıçlarından Örnekler.

Enes Batur, Orkun Işıtmak gibi farklı mekânlarda video çekmektedir. Videolarında herhangi bir giriş jeneriğinin verilmemesi ve videolarının başlangıçlarının amatör görünüm, doğal bir hava yaratmaktadır. Videolar genellikle dinamik bir yapıya sahiptir. Ayrıca Enes Batur videolarında çeşitli marka ve ürün tanıtımları da yer almaktadır.

Enes Batur videoları süre olarak özellikle son yıllarda genellikle 20 dakikanın üzerindedir. İlk dönem video süreleri ise daha düzensizdir. 10 dakikayı aşan videoların yanı sıra 1 saati aşan videoları da bulunmaktadır. Oyun tanıtım ve analizleri daha uzunken eğlence odaklı videolar daha kısa tutulmuştur. Diğer yandan yıllar içinde Enes Batur videolarında teknik ve içerik açısından büyük farklılıklar olduğu göze çarpmaktadır. Video içerikleri çeşitlenmiş, eğlence odaklı videolar ağır basmaya başlamış ve teknik olarak videolar daha profesyonel bir görünüme kavuşmuştur. Başlangıçta oyun videolarının hitap ettiği kitle eğlence videoları ile genişletilmiştir. Diğer yandan Enes Batur YouTube kanalındaki video açıklamalarında yazım hataları ve devrik cümleler dikkat çekmektedir.

Çalışma kapsamında Enes Batur'un YouTube kanalındaki 1817 videonun tamamının incelemesi mümkün olmadığından incelenecek videolar sınırlandırılmıştır. Kanalın zaman içinde geçirmiş olduğu dönüşümün net bir biçimde ortaya konulabilmesi ve YouTuberın kimlik temsiline ilişkin detaylı bir analiz yapılabilmesi için 2014 ve 2019 yıllarından birer video, kullanıcı yorumları da ele alınarak incelenmektedir. Bu unsurlar üzerinden Enes Batur'un YouTube kanalında yarattığı kimlik temsilinin abonelerde/ izleyicilerde nasıl karşılık bulduğu yorumlanmıştır.

Enes Batur kanalında analiz çerçevesinde ele alınan ilk video 2014'te yayınlanan ve ilk dönem videolarından biri olan "VLOG - Fırat ve Enes Soru Cevaplıyoruz" başlıklı videodur. 208 binin üzerinde izlenen video, genellikle oyun videoları çeken Enes Batur'un ilk vlog videolarından biridir. 9 dakika olan video, abonelerin Enes Batur’a yönelttiği sorulara verilen cevapları içermektedir. Ev ortamında çekilen ve görüntü kalitesi çok iyi olmayan videoda sorular genellikle Enes Batur'un kişisel yaşamına yöneliktir. 951 yorum yapılan videoda özellikle son yorumlar yeni aboneler tarafından yazılmıștır. 
Enes Batur'un ele alınan ikinci videosu ise 11 Ekim 2019'da yayınlanan "24 SAAT BOYUNCA TEK RENK CHALLENGE" başlıklı, 6 milyon 770 binden fazla izlenen videodur. Süresi 25:02 olan video, çok kısa sürede iyi bir çıkış yakalamış ve izlenme sayısı 7 milyona yaklaşmıştır. Bu videoda Enes Batur üç arkadaşıyla eğlenceye dayalı bir günlük deneyimini izleyiciye aktarmaktadır. 40.857 yorumun yapıldığı videoda tamamen eğlenceye dayalı bir deneyim merak uyandırıcı bir şekilde sunulmaktadır.

Enes Batur'a ait videolar, genellikle zengin bir yaşamın özendirici bir biçimde sunumunu içermektedir. Özellikle geçmişten bugüne yükselen şöhret, YouTuber kimliği ile öne çıkan Enes Batur'a aynı zamanda ünlü etiketlemesi yapıldığını göstermektedir. Aboneler, Enes Batur'un yaşamının tüm ayrıntılarını merak etmekte ve pek çok soru yöneltmektedir. Enes Batur'un özellikle eğlenceye dayalı son dönem videolarında gidilen mekânlar, binilen araçlar ve diyaloglar, istenilen her şeyin sınırsızca yapılabildiği bir dünya imajı yaratmaktadır. Videolarda para ve zenginlik vurgusu dikkat çekmektedir. Dolayısıyla Enes Batur da birçok YouTuber gibi yaşam tarzına hayranlık duyulan, özenilen biri olarak görülmektedir.

YouTube kanalı üzerinden inşa edilen Enes Batur kimliği, Orkun Işımak için de geçerli olan; gündelik yaşamda karşılaşılan çeşitli sorunlardan uzak, eğlence odaklı bir yaşamı olan ve istenen her şeyi kolayca yapabilme lüksüne sahip bir kimlik temsiline denk düşmektedir. Enes Batur'un sıradan biriyken 11 milyonu aşan ve yüksek miktarlarda para kazandıran abone ağına sahip olması özendirici yanını oluşturmaktadır. Enes Batur kimliği genel olarak doğal, eğlenceli, macera ve eğlence odaklı bir hayat yaşayan, "ünlü" bir kişi biçiminde inşa edilmektedir. Bu kimliği ile Enes Batur hem sosyal medya hem de geleneksel medyada yer alabilme imkânına da erişmiştir. Abone sayıları, izlenme oranları ve popülaritesi üzerinden YouTuber kimliği pekişen Enes Batur aynı zamanda gerek medya gerekse aboneler tarafından "ünlü” olarak görülmekte, dolayısıyla magazinel yönleriyle yeniden üretilmektedir. Bu yönüyle YouTuber kimliği Enes Batur'a şöhret dünyasının kapısını aralayarak ünlülerle bir arada olabilmenin önünü açmıștır.

Çalışma kapsamında ele alınan her iki YouTuberın da neşeli ve enerjik bir başlangıçla konuya girdiği ve son derece coşkulu, samimi ve doğal bir anlatım tarzını benimsediği söylenebilmektedir. Bu kişilerin anlatım yapısında 'tüm bu yaptıklarım sizin için', 'sizin için ne kadar çok şey yaptım' algısı yaratacak söylemler olduğu da görülmektedir. Ayrıca kanal aboneleri de bu algıyı destekleyici yorumlar yapmaktadır.

Genel olarak her iki YouTuber incelendiğinde onların, YouTube platformunda hızla yükselmesi, takipçi sayılarının ve izlenme oranlarının devamlı bir şekilde artması buna bağlı olarak da maddi kazançlarının çoğalması, geleneksel medyada karşımıza çıkan birden şöhret olma ve büyük kazanç sağlama hikâyelerinin yeni medyadaki karşılığını oluşturmaktadır. Diğer taraftan reklam gelirinden büyük pay alan YouTuberlar, kolay yoldan para kazanan ve bu geliri bir mekâna bağlı kalmadan sağlayan, maddi kazancını gezerek, eğlenerek elde eden bir kimlik temsili ile karşımıza çıkmaktadır. Dolayısıyla hem maddi kaygısı olmayan hem de büyük bir hayran kitlesine sahip olan bu kişiler hayranlık duyulan ve özenilen bir yaşamı tasvir etmektedir. Kusursuz bir yaşam profili sunan YouTuber, onun gibi olmak için çabalayan ya da onun gibi olamadığı için mutsuz olan bir hayran kitlesi de yaratmaktadır. 


\section{Tartışma ve Sonuç}

Kişide kalıcı olan aynılığı tanımlayan kimlik, toplumdaki iç ve dış dinamiklere bağlı olarak şekillenmektedir. Bireyin diğerleri ile olan benzerlik ve farklılıklarından doğan kimlik bu anlamda toplumsal bir ürün olma özelliği taşımaktadır.

Sosyolojik olarak toplumsal bir inşa sürecine dayanan kimlik, yeni iletişim teknolojilerinin insan yaşamını her yönüyle kuşatması ve insanın eylem ve söylemleri ile siber uzamda var olmaya başlaması çerçevesinde sanal olarak inşa edilen ve sanal olarak yeniden üretilen bir yapıya bürünmüştür. 'Sanal' biçiminde tanımlanan bu kimlik, kişinin sosyal ağlarda yapıp ettikleri ve kim olmak istediği ile doğrudan ilintilidir. Bu anlamda sanal kimlik, kişinin gerçek hayattaki kimliğinden uzak ve aynı zamanda olmak istediği hayali bir kimlik temsiline denk düşmektedir.

Teknoloji, kimlik yapılandırmaları noktasında kullanıcılara geniş bir hareket alanı yaratmıștır. Dijital teknolojiler aracılığıyla insan yaşamında önemli bir yer kaplamaya başlayan sosyal ağlar, kişinin gerçek kimliğini gizleyerek, abartarak veya çarpıtarak var olabildiği bu anlamda istediği kimliğe bürünebildiği bir ortam sunmaktadır. Diğer yandan sosyal ağların kullanma pratikleri de (beğenme ve yorum yapabilme özellikleri v.s.) kişinin sanal kimlik inşa etmesi noktasında itici bir güç olmaktadır. Bireyin takdir edilme, beğenilme arzusu, takipçi veya abone sayısını arttırma isteği ve sosyal ağlar aracılığıyla para kazanma tutkusu kişiye yeni bir 'ben' inşa etmenin kapılarını açmaktadır. Bununla birlikte sanal kimlik, her bir sosyal ağın işleyiş pratiği ekseninde şekillenmektedir. Bir Instagram kullanıcısı çoğunlukla fotoğraf paylaşımında bulunurken, Twitter kullanıcısı daha çok yazılı mesajlar paylaşmakta, YouTube kullanıcısı ise video aracılığı ile kendini ifade etmektedir.

$\mathrm{Bu}$ çalışma YouTube ortamında YouTuberlar tarafından inşa edilen sanal kimlik temsili üzerine odaklanmaktadır. Bu bağlamda çalışmada YouTuber kimliğine ilişkin bir çerçeve ortaya koymak ve bu kimliği tüm yönleriyle tanımlayabilmek için Socialblade verilerine göre en fazla abonesi olan iki kişisel YouTube kanalı seçilmiş ve betimsel analiz yöntemi ile incelenmiştir. Çalışma kapsamında ele alınan YouTube kanallarının künyesi çıkarılmış, her bir kanaldan geçmiş ve güncel iki video belirlenerek YouTuber kimliğine ilişkin detaylı bir analiz gerçekleştirilmiştir.

Çalışma kapsamında ele alınan YouTube kanalları analiz edildiğinde gündelik hayatın sıkıcılığından ve monotonluğundan uzak, herhangi bir mekâna bağlı kalma zorunluluğu olmadan kazanç sağlayan, özgürce gezen, birçok şeyi yapıp etme becerisine sahip, iyi iletişim kuran, bakımlı, kibar, doğal ve dost canlısı gibi birçok olumlu sıfatı kendisinde toplayan, kısacası mükemmeli temsil eden bir YouTuber kimliği olduğu gözlenmiştir. Bu temsiller sosyal ağlarda görülen mutlak mükemmellik gösterisine denk düşmektedir. Dolayısıyla incelenen YouTube kanallarında doğallığın yeniden üretildiği, doğal olanın yapaylaştığl, özgürlüğün ve mutluluğun koşulsuz bir şekilde gerçekleștiği bir dünya tasviri dikkat çekmektedir.

Çalışma kapsamında ele alınan YouTuberların kimlik temsilleri oldukça benzer nitelikler taşımaktadır. Bununla birlikte kimlik temsilinin söylemin yanı sıra görsel imajlar yardımıyla desteklendiği görülmektedir. YouTube videoları üzerinden yaratılan YouTuber kimliği; abone sayıları, izlenme oranları ve popülaritenin artmasıyla pekişmektedir. Buna bağlı olarak YouTuberlar hem sosyal medyada hem de geleneksel medyada yer almaktadır. Bu yönüyle YouTuberların ortaya koyduğu yükselen imaj ve maddi 
güç, özendirici bir nitelik kazanmaktadır. YouTube fenomeni veya YouTuber/Vlogger olarak tanımlanan kişilerin şöhrete dayalı olarak gerçekleșen kimlik inşası, 'bizden biri' olma imajı çerçevesinde geleneksel medyada yer alan "ünlü" statüsünün ötesinde bir karşılık bulmaktadır.

\section{Kaynakça}

Armağan, A. (2013). Kimlik yapılarında değişim ve sanallaşan kimlik sunumları: öğrenciler üzerinde bir araștırma. Akademik Bakış Dergisi, 37, 1-20. Erişim adresi: http:// www.acarindex.com/dosyalar/makale/acarindex-1423867752.pdf

Bauman, Z. (2013). Sosyolojik düşünmek. (A. Yılmaz, çev.). İstanbul: Ayrıntı Yayınları.

Bayart, J. F. (1999). Kimlik yanılsaması, (M. Boralı, Çev.). İstanbul, Metis Yayınları.

Binark, M., \& Bayraktutan-Sütcü, G. (2008). Silkroad online'da sanal cemaat inşası ve türk klan kimliği. M. Akgül ve diğerleri (Yay. Haz.). Inet-tr'08 - XIII. Türkiye'de İnternet Konferansı, Ankara, Türkiye Bildiriler içinde (s.105-114). Ankara: Orta Doğu Teknik Üniversitesi.

Burgess, J., Green, J. (2009). YouTube: online video and participatory culture. Cambridge, UK: Polity Press.

Castells, M. (2013). Enformasyon çağl: ekonomi, toplum ve kültür. İkinci Cilt: Kimliğin gücü. (E. Kılıç, Çev.). İstanbul: İstanbul Bilgi Üniversitesi Yayınları.

Castells, M. (2008). Ağ toplumunun yükselişi. (E. Kılıç, Çev.). İstanbul: İstanbul Bilgi Üniveritesi Yayınları.

Castells, M. (2009). Communication power. New York: Oxford University Press.

Chandler, D., Munday, R. (2018). Medya ve iletişim sözlüğü. (B. Taşdemir, Çev.). İstanbul: İletişim Yayınları.

Hall, S. (1998). Eski ve yeni kimlikler, eski ve yeni etniklikler. A. D. King (yay. Haz). Kültür, Küreselleşme ve Dünya-Sistemi içinde. (G. Seçkin ve Ü. Yolsal, Çev.). (s.63-96). Ankara: Bilim ve Sanat Yayınları.

Hunt, L. (2018). Küresel çağda tarih yazmak. (E. Kayserilioğlu, Çev.). İstanbul: Küre Yayınları.

Kellner, D. (2013). Medya gösterisi. (Z. Paşalı, Çev.). İstanbul: Açılım Kitap.

Manovich, L. (2001). The language of new media Cambridge: Massachusetts Institute of Technology.

Miller, K. (2012). Playing along: digital games, youtube, and virtual performance. New York: Oxford University Press.

Morley, D., Robins, K. (1997). Kimlik mekânları küresel medya, elektronik ortamlar ve kültürel sınırlar. (E. Zeybekoğlu, Çev. ). İstanbul: Ayrıntı Yayınları.

Morva, O. (2014). Goffman"ın dramaturjik yaklaşımı ve dijital ortamda kimlik tasarımı: sosyal paylaşım ağı facebook üzerine bir inceleme. S. Çakır (Yay. haz.). Medya ve tasarım içinde (s. 231-255.). İstanbul: Urzeni.

Socialblade. (t.y.). Enes Batur. Erişim adresi: https://socialblade.com/youtube/user/ newdaynewgame 
Socialblade. (t.y.). Orkun Işıtmak. Erişim adresi: https://socialblade.com/youtube/user/ thepersica

Timisi, N. (2005). Sanallığın gerçekliği: internetin kimlik ve topluluk alanlarına girişi, internet toplum kültür. M. Binark ve B. Kılıçbay (Yay. hHaz.), İnternet toplum kültür içinde (s.89-105). Ankara: Epos Yayınları.

Yıldırım, A. \& Şimşek, H. (2018). Sosyal bilimlerde nitel araştırma yöntemleri. Ankara: Seçkin Yayıncılık.

Youtube, (2012). Enes Batur. Erişim adresi: https://www.youtube.com/user/ newdaynewgame

Youtube, (2010). Orkun Işıtmak. Erişim adresi: https://www.youtube.com/user/ ThePersica 


\title{
Identity Building in New Media: A Review on YouTuber Identity
}

\author{
İbrahim Etem Zinderen (Asst. Prof. Dr.)
}

\section{Extended Abstract}

Becoming an inseparable part of our daily lives, new communication technologies have brought about new patterns and changes in social terms. One of the most important changes experienced in the sociological context emerged on the identity axis. Expressing the individual's subjective sense of selfdom, the identity is shaped within the framework of the sameness and discrepancy of individuals with others. Therefore, the identity has a socially constructed nature. In this context, when social media platforms that come into our lives with the discovery of Web 2.0 are considered as a social activity area, one can speak of identity building process within such framework. This form of identity produced in the digital environment is identified as virtual identity. Virtual identity refers to an identity that emerges through what we do in the new media environment and the way we present ourselves. However, virtual identity is built within the context of social and personal relationships that are established through social networks. Identity built in the new media environment can be an extension of one's true identity as it can be very different on the other hand. Technology has created a wide range of mobility for the users in terms of identity configurations. Social networks, which have started to occupy an important place in human life through digital technologies, provide an environment in which one can impersonate in this sense, by concealing, exaggerating or distorting one's true identity. On the other hand, the practices of using social networks (features of liking and commenting etc.) are a driving force for the person to build virtual identity. The desire of the individual to be appreciated and liked, to increase the number of followers or subscribers and his/her passion to make money through social networks paves the way for building a new 'me'. However, virtual identity is shaped within the axis of the way each social network works. While an Instagram user mostly shares photos, the Twitter user mostly shares text messages and the YouTube user expresses himself through video. This study focuses on YouTubers and the Youtube environment, which is a popular social media platform. The main purpose of the study is to evaluate the construction of virtual identities within the framework of YouTubers, to describe the Youtuber identity and to create the map of such identity. Two individual YouTube channels with the highest number of subscribers in Turkey according to the data of Socialblade has been chosen as sample. These channels are YouTube channels created by Orkun Işitmak and Enes Batur under their own names. The video channels discussed in the study were examined in detail and analyzed within the context of identity construction. These analyzes were elaborated by selecting one sample video both from the first period and latest period of the channels. In this context, Orkun Işıtmak's videos titled "ILK VLOG! - Duyurular, Gelen Sorular, Oynanacak Oyunlar - Cumartesi BLOGU" which was published on October 12, 2019 and reached 38.158 views and "ÖZEL BİSİKLETLER İLE DRİFT YARIȘI! (KAZA YAPTIM!)" which was published on October 5, 2019 and reached 1.089 .165 views have been discussed. Enes Batur's video from his period, reaching 208.310 views, titled "VLOG - Firat ve Enes Soru Cevapliyoruz" and dated August 30, 2014 and the video titled "24 SAAT BOYUNCA TEK RENK CHALLENGE", published on October 11, 2019 reaching 6.772.006 views were analyzed. It can be said that both YouTubers discussed in the scope of the study entered the subject with a cheerful and energetic start and adopted a very enthusiastic, sincere and natural style of expression. It is also observed that these 
people have discourses that will create the perception of 'all this I have done for you, and how much I have done for you." Moreover, channel subscribers also make comments supporting such perception. In general, when both YouTubers are examined, their rapid rise on YouTube platform, the continuous increase of their subscribers and their viewing durations and therefore the increase of their financial gains constitute the reflections of the stories themed suddenly becoming so famous and earning great amount of money in the new media. On the other hand, YouTubers, who receive a large share of advertising revenue, demonstrate an identity representation that earns money in an easy way, and makes their financial gains by visiting and having fun. Therefore, these people who do not have financial concerns and have a large fan base depict a life that is admired and emulated. Offering an impeccable life profile, the YouTuber also creates a fan base that strives to be like her/him or is unhappy that they can't be like her/him. The rising image and financial power demonstrated by YouTubers represent an encouraging characteristic. In this context, the identity representations of the YouTubers demonstrate quite similar characteristics. Moreover, it is observed that such identity representation is supported by visual images as well as discourse. The YouTuber ID created through YouTube videos is reinforced by the increase in the number of subscribers, view rates and popularity. Accordingly, YouTubers appear on both social and traditional media. On the other hand, the fame-based identity building of people identified as the YouTube phenomenon or YouTuber / Vlogger finds a response beyond the "celebrity" status of traditional media within the framework of the image of being 'one of us'. In summary, both channels have been observed to represent a YouTuber ID that is free from the boringness and monotony of everyday life, earning money without any obligation to stick to any place, being free to travel, having ability to do many things, establishing good communication, getting positive attributes such as well-maintained, polite, natural and friendly and representing the perfect with this aspect.

Keywords: New Media, Identity, Virtual Identity, YouTuber Identity. 
